\title{
Evaluation of Effectiveness of Stellate Ganglion Block Treatment of Sudden Sensorineural Hearing Loss
}

\author{
Seung Yoon Han ${ }^{\mathbb{D}}$, Jin Lee ${ }^{\mathbb{D}}$, Hyungbon Koo ${ }^{\mathbb{D}}$, and Juyong Chung ${ }^{\mathbb{D}}$ \\ Department of Otorhinolaryngology-Head and Neck Surgery, Wonkwang University College of Medicine, Iksan, Korea
}

\author{
돌발성 감각신경성 난청 환자에서 성상신경절차단술의 효과에 대한 평가 \\ 한승윤 · 이 진 · 구형본 · 정주용 \\ 원광대학교 의과대학 이비인후과학교실
}

Received October 18, 2021

Revised December 28, 2021

Accepted January 5, 2022

Address for correspondence

Juyong Chung, MD, PhD

Department of Otorhinolaryngology-

Head and Neck Surgery,

Wonkwang University

College of Medicine,

895 Muwang-ro, Iksan 54538, Korea

Tel $+82-63-859-1489$

Fax $+82-63-858-3922$

E-mail claudia7974@naver.com
Background and Objectives Sudden sensorineural hearing loss (SSNHL) is characterized by sudden onset of impaired hearing, and systemic steroid is the most widely accepted treatment option for it. The aim of this study is to evaluate the effectiveness of stellate ganglion block (SGB) as a treatment option for SSNHL.

Subjects and Method A total of 318 patients diagnosed with SSNHL were treated with systemic steroid and SGB (SGB group, 127 patients) or systemic steroid only (non-SGB group, 191 patients). Hearing improvement was defined as a hearing gain of more than slight improvement using Siegel's criteria.

Results The SGB group did not show any significant effects on hearing improvement compared with the non-SGB group (60\% vs. $65 \%$ ). However, some patients with profound hearing loss of more than $90 \mathrm{~dB}$ have recovered above average after the SGB treatment. Also, we used multiple regression analysis to ascertain which factors influenced hearing recovery, and found that the initial pure-tone audiometry thresholds at $2000 \mathrm{~Hz}$ and $4000 \mathrm{~Hz}$ were statistically associated with hearing recovery.

Conclusion In conclusion, SGB did not show a clear therapeutic effect, but suggested the possibility of treatment for improving the inner ear circulation of patients with profound hearing loss. Korean J Otorhinolaryngol-Head Neck Surg 2022;65(2):86-92

Keywords Stellate ganglion; Steroids; Sudden hearing loss.

\section{서 론}

일측성 돌발성 감각신경성 난청(sudden sensorineural hearing loss)은 순음청력검사상 3개 이상의 연속된 주파수 에서 $30 \mathrm{~dB}$ 이상의 청력저하가 3 일 내에 갑자기 발생하는 감 각신경성 난청으로 정의된다. ${ }^{1)}$ 때로는 이명이나 이충만감, 현 기증을 동반하는 질병이며, ${ }^{2)}$ 알려진 원인 질환으로는 바이러 스 감염, 와우막 파열, 자가면역성 질환, 내이의 혈류장애 등

This is an Open Access article distributed under the terms of the Creative Commons Attribution Non-Commercial License (https://creativecommons.org/licenses/by-nc/4.0) which permits unrestricted non-commercial use, distribution, and reproduction in any medium, provided the original work is properly cited.
이 있다. ${ }^{3)}$ 한국에서의 연간 유병률은 10 만 명당 10 명 이상 발 생한다고 알려져 있다. ${ }^{4}$

지금까지 돌발성 난청에 효과적이라고 알려진 치료는 전신 스테로이드 요법(systemic steroid)과 고실 내 스테로이드 주 사(intratympanic dexamethasone, ITD)가 있으며, ${ }^{5)}$ 보조요 법으로 항바이러스제,, ${ }^{6}$ 혈관확장제, ${ }^{7)}$ 항응고제, ${ }^{8)}$ 고압산소치 료, ${ }^{9)}$ 성상신경절차단술(stellate ganglion block, SGB) 치료 ${ }^{10)}$ 등이 사용되고 있다.

이중 성상신경절차단술(SGB)은 1976년 Haug 등 ${ }^{11}$ 에 의해 처음 돌발성 난청의 치료법으로 보고된 이후 여러 기관에서 연구를 발표한 방법으로, 경추 교감신경총(cervical sympa- 
thetic trunk)에 국소마취제를 주사하여 교감신경차단과 혈관 확장을 통해 혈류 증가를 일으키는 방법이다. 이러한 이론을 근거로 내이 혈류 장애도 개선시킬 것으로 기대되어 돌발성 난청의 치료에 사용하고 있다.

하지만 그 효과에 대해서는 명확하게 정립되지 않았는데, 돌발성 난청 환자에서 전신 스테로이드 요법과 SGB 병행치료 를 했을 때 스테로이드 단독 치료에 비해 더 높은 회복률을 보였다는 연구 ${ }^{12)}$ 가 있었던 반면, $70 \mathrm{~dB}$ 의 고도난청 이하의 청 력저하 환자에서만 일부 효과가 있었다는 발표 ${ }^{13)}$ 가 있는 등 연구마다 그 결과에 차이를 보이고 있다.

따라서 본 연구에서는 돌발성 감각신경성 난청 환자에서 전신 스테로이드 요법, 고실 내 스테로이드 주사와 통합치료 법으로서의 SGB가 미치는 효과에 대해 알아보고자 하였다.

\section{대상 및 방법}

2015년 1월부터 2019년 12월까지 원광대학교병원 이비인 후과에 청력저하를 주소로 내원, 일측성 돌발성 난청을 진단 받은 총 318 명의 환자를 대상으로 후향적 연구를 시행하였 다. 이 연구는 본원의 기관윤리심의위원회의 심의를 통과하였 다(IRB No. WKUH 2022-02-006). 이 중 SGB를 시행한 환 자는 127 명, 시행하지 않은 환자는 191명이었으며, 모든 환자 에게 전신 스테로이드 요법과 고실 내 스테로이드 주사(ITD) 를 시행하였다. 전신 스테로이드는 methylprednisolone을 사 용했으며, 65세 이상의 고령이거나 고혈압 혹은 당뇨가 있는 환자는 하루에 몸무게 $\mathrm{kg}$ 당 $0.8 \mathrm{mg}$ (prednisolone $1 \mathrm{mg} / \mathrm{kg}$ ), 그 밖의 경우에는 $\mathrm{kg}$ 당 $1.6 \mathrm{mg}$ (prednisolone $2 \mathrm{mg} / \mathrm{kg}$ )을
7일간 처방하였고, 이후 하루에 $30 \mathrm{mg}$ 씩 최대 5일간 테이퍼 링 요법을 시행하였다. 이러한 용량은 기존의 고용량 스테로 이드 치료법보다 2-4배 이상 높은 초고용량의 스테로이드 치 료에 의해 빠르고 유의한 청력 회복에 도움이 되며, 외림프 내 cortisol 레벨을 더 크게 증가시킨다는 보고들에 기반한 것으 로, ${ }^{14,15)}$ 특히 스테로이드 부작용 위험이 적은 65 세 미만의 고 혈압, 당뇨 같은 기저질환이 없는 환자들에게서 청력호전의 더 큰 효과를 경험했기 때문에 임상적으로 사용하고 있다. ITD는 dexamethasone $0.5 \mathrm{mg}$ 을 하루 한 번씩 4일간 시행하였다.

$\mathrm{SGB}$ 는 마취통증의학과에 의뢰하여 입원 3-4일째부터 매일 시행하였다. 초음파를 이용하여 시행하였는데, 제7경추의 극 상돌기를 확인한 뒤 위쪽으로 올라가 제6경추의 극상돌기를 찾고, 외측으로 경동맥(carotid artery)과 경장근(longus colli muscle)을 확인한 뒤 경동맥 아래쪽의 sympathetic trunk 부위를 찾아서 mepivacaine $0.25 \%$ 희석용액을 약 $2 \mathrm{~mL}$ 주 사하였다(Fig. 1). 환자의 입원 기간은 총 7-8일이었으며, 따 라서 총 4-5회 SGB를 시행하였다.

이후 환자를 $\mathrm{SGB}$, non-SGB 그룹으로 분류를 하고 내원 당시부터 매일 순음청력검사(pure-tone audiometry, PTA) 를 시행하였으며, 퇴원 후 약 2주 간격으로 외래 추적 관찰을 시행하였다. 최종 청력역치는 치료 시작 2 개월 뒤의 청력 측 정값으로 하였다. 이때 회복되는 청력에 대하여 Siegel's criteria를 적용하여 6분법에 따른 청력역치의 평균값이 치료 전 에 비해 $25 \mathrm{~dB}$ 이상 회복된 경우 Group I (complete recovery), $15 \mathrm{~dB}$ 이상 회복되었으며 최종 청력역치의 평균값이 25-45 dB인 경우 Group II (partial recovery), $15 \mathrm{~dB}$ 이상 회복되었으며 최종 청력역치의 평균값이 $45 \mathrm{~dB}$ 초과인 경우
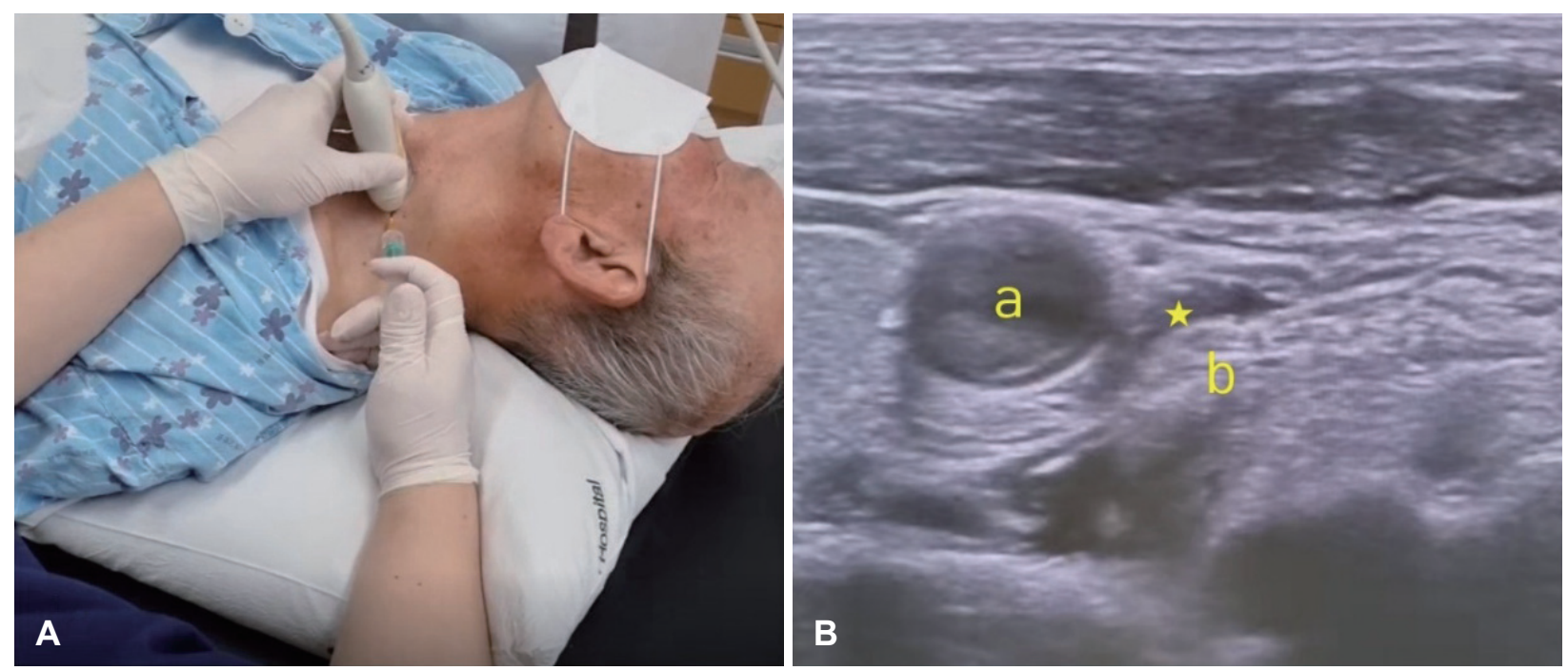

Fig. 1. A photography of performing stellate ganglion block on a patient diagnosed with sudden sensorineural hearing loss and an ultrasound finding showing the injection site. A: An anesthesiologist is performing stellate ganglion block using ultrasound. B: Local anesthetic is injected into the sympathetic trunk $(\star)$ between the carotid artery (a) and longus colli muscle (b). 
Group III (slight improvement), $15 \mathrm{~dB}$ 미만 회복되었거나 최종 청력역치의 평균값이 $75 \mathrm{~dB}$ 초과인 경우 Group IV (no improvement)로 정의하고 환자를 분류하였다(Table 1).

$\mathrm{SGB}$ 그룹에서 기저질환(고혈압, 당뇨, 고지혈증, 심혈관질 환)과 연령대(10-70대)가 동일한 non-SGB 그룹의 환자 중 초기 청력역치의 평균값(6분법)이 $5 \mathrm{~dB}$ 이내로 차이가 나는 환자를 선정하여 매칭하였다. 매칭되는 환자를 찾을 수 없는 $\mathrm{SGB}$ 그룹 환자들은 연구에서 제외하였고, 마찬가지로 선정 되지 않은 non-SGB 그룹 환자들도 연구에서 제외하였다. 그 결과 $\mathrm{SGB}$ 그룹 127 명 중 57 명을 제외한 70명, non-SGB 그룹 191명 중 121명을 제외한 70명, 총 140 명의 환자에 대해 다시 비교연구를 하였다. 이때 청력역치에 따른 $\mathrm{SGB}$ 의 효과 를 비교해 보고자 초기 청력역치의 평균값(6분법) $40 \mathrm{~dB}$ 미 만을 그룹 $\mathrm{A}, 40 \mathrm{~dB}$ 이상 $70 \mathrm{~dB}$ 미만을 그룹 $\mathrm{B}, 70 \mathrm{~dB}$ 이상 을 그룹 $\mathrm{C}$ 로 분류하여 연구를 시행하였다.

Table 1. Siegel's criteria

\begin{tabular}{lc}
\hline \multicolumn{1}{c}{ Type } & \multicolumn{1}{c}{ Hearing recovery } \\
\hline I. Complete recovery & $\begin{array}{l}\text { Final hearing better than } 25 \mathrm{~dB} \\
\text { II. Partial recovery }\end{array}$ \\
$\begin{array}{c}\text { More than } 15 \mathrm{~dB} \text { gain, final hearing } \\
25-45 \mathrm{~dB}\end{array}$ \\
III. Slight improvement & $\begin{array}{c}\text { More than } 15 \mathrm{~dB} \text { gain, final hearing } \\
\text { poorer than } 45 \mathrm{~dB} \\
\text { Less than } 15 \mathrm{~dB} \text { gain, final hearing } \\
\text { IV. No improvement }\end{array}$ \\
\hline
\end{tabular}

\section{결 과}

초기 청력역치 평균값에서 $\mathrm{SGB}, \mathrm{non}-\mathrm{SGB}$ 그룹 간에 유 의한 차이가 존재했기 때문에 교란변수로 인한 밸런스를 맞 추기 위해 고혈압, 당뇨, 고지혈증, 심혈관질환 유무, 나이, 초 기 PTA 평균값을 매칭하였다(Table 2).

매칭한 뒤 SGB, non-SGB 두 그룹 간에 순음청력검사상 $500,1000,2000,4000 \mathrm{~Hz}$ 각 주파수 및 평균청력역치에 유 의미한 차이는 없었다(Table 3 ).

\section{Siegel's criteria에 따른 grade의 평균}

Siegel's criteria의 기준에 따라 grade를 평가하였고 SGB 그룹의 평균값은 $2.36( \pm 1.341), \mathrm{non}-\mathrm{SGB}$ 그룹의 평균값은 2.29 ( \pm 1.353$)$ 로 유의미한 차이는 없었다(Fig. 2).

\section{치료 전 후 청력역치의 차이}

순음청력검사상 500, 1000, 2000, $4000 \mathrm{~Hz}$ 각 주파수별 청력역치 및 평균역치값에 대해 치료 전에서 치료 후의 값을 뺀 차이를 각각 P500, P1000, P2000, P4000, P average로 정의하고 $\mathrm{SGB}, \mathrm{non}-\mathrm{SGB}$ 각 그룹별로 평균값을 조사하였다. $\mathrm{P} 500$ 은 SGB 그룹이 20.97, non-SGB 그룹이 24.86이었고 $\mathrm{P} 1000$ 은 SGB 그룹 18.29, non-SGB 그룹 21.86, P2000은 $\mathrm{SGB}$ 그룹 16.86, non-SGB 그룹 20.36, P4000은 SGB 그룹

Table 2. Prognostic factors of patients before matching

\begin{tabular}{lccc}
\hline & SGB group $(\mathrm{n}=127)$ & Non-SGB group $(\mathrm{n}=191)$ & $\mathrm{p}$ value \\
\hline Age & $51.40 \pm 15.94$ & $51.58 \pm 17.58$ & $>0.05$ \\
Initial PTA at $500 \mathrm{~Hz}(\mathrm{~dB})$ & $67.80 \pm 25.03$ & $52.43 \pm 26.25$ & $<0.001$ \\
Initial PTA at $1000 \mathrm{~Hz}(\mathrm{~dB})$ & $67.24 \pm 26.58$ & $50.68 \pm 28.48$ & $<0.001$ \\
Initial PTA at $2000 \mathrm{~Hz}(\mathrm{~dB})$ & $64.53 \pm 28.00$ & $49.88 \pm 28.89$ & $<0.001$ \\
Initial PTA at $4000 \mathrm{~Hz}(\mathrm{~dB})$ & $65.08 \pm 27.70$ & $54.32 \pm 28.19$ & $<0.001$ \\
Initial average PTA (dB) & $66.07 \pm 25.48$ & $51.31 \pm 26.84$ & $<0.001$ \\
HTN (\%) & $23.6(30)$ & $26.2(50)$ & $>0.05$ \\
DM (\%) & $14.9(19)$ & $14.1(27)$ & $>0.05$ \\
Hyperlipidemia (\%) & $6.3(8)$ & $12.6(24)$ & $>0.05$ \\
Cardiovascular disease (\%) & $7.9(10)$ & $7.3(14)$ & $>0.05$ \\
\hline
\end{tabular}

SGB, stellate ganglion block; PTA, pure-tone audiometry threshold; HTN, hypertension; DM, diabetes mellitus

Table 3. Prognostic factors of patients after matching

\begin{tabular}{lccc}
\hline & SGB group & Non-SGB group & p value \\
\hline Age & $49.86 \pm 15.94$ & $50.46 \pm 16.04$ & $>0.05$ \\
Initial PTA at $500 \mathrm{~Hz}(\mathrm{~dB})$ & $61.00 \pm 24.37$ & $59.71 \pm 27.36$ & $>0.05$ \\
Initial PTA at $1000 \mathrm{~Hz}(\mathrm{~dB})$ & $58.64 \pm 27.44$ & $58.43 \pm 28.62$ & $>0.05$ \\
Initial PTA at $2000 \mathrm{~Hz}(\mathrm{~dB})$ & $55.57 \pm 28.05$ & $56.86 \pm 27.84$ & $>0.05$ \\
Initial PTA at $4000 \mathrm{~Hz}(\mathrm{~dB})$ & $56.57 \pm 27.71$ & $57.07 \pm 27.63$ & $>0.05$ \\
Initial average PTA (dB) & $57.67 \pm 25.59$ & $57.89 \pm 26.73$ & $>0.05$ \\
\hline
\end{tabular}

SGB, stellate ganglion block; PTA, pure-tone audiometry threshold 
16.86, non-SGB 그룹 14.93, P average는 SGB 그룹 18.02, non-SGB 그룹 20.70가 나왔다. 두 그룹 모두 치료 후에 모 든 주파수 및 평균값에서 청력이 회복되었으나 통계적으로 $\mathrm{SGB}$ 와 non-SGB 두 그룹 간에 유의한 차이는 보이지 않았 다(Fig. 3).

\section{초기 청력역치평균에 따른 그룹별 Siegel's criteria의} grade

초기 청력역치평균에 대해 $40 \mathrm{~dB}$ 미만을 그룹 $\mathrm{A}(\mathrm{n}=34)$, $40 \mathrm{~dB}$ 이상 $70 \mathrm{~dB}$ 미만을 그룹 $\mathrm{B}(\mathrm{n}=58), 70 \mathrm{~dB}$ 이상을 그 룹 C $(n=48)$ 로 나누고 각 그룹에서 SGB 그룹과 non-SGB 그룹에 대해 Siegel's criteria의 grade를 조사, 비교하였다. 그룹 $\mathrm{B}$ 와 $\mathrm{C}$ 는 그룹 $\mathrm{A}$ 에 비해 통계적으로 유의하게 grade가 높은 것으로 나타났지만, $\mathrm{SGB}, \mathrm{non}-\mathrm{SGB}$ 그룹 간에 차이는 보이지 않았다(Fig. 4).

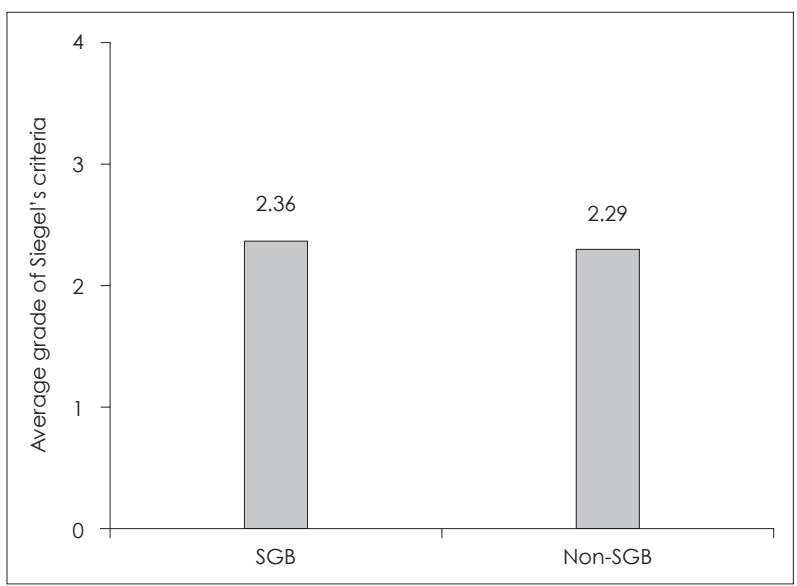

Fig. 2. There is no difference in average grade of Siegel's criteria between the two groups ( $p>0.05, \chi^{2}$ test). SGB, stellate ganglion block.

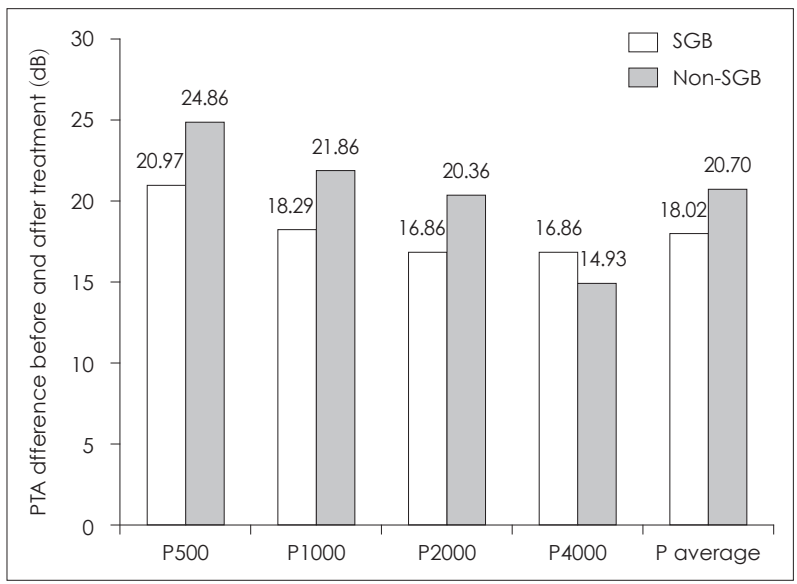

Fig. 3. There is no difference in PTA difference between the two groups at all frequencies ( $p>0.05, \chi^{2}$ test). PTA, pure-tone audiometry threshold; SGB, stellate ganglion block.

\section{청력역치에 따른 그룹별 회복률}

Siegel's criteria grade I, II, III을 치료 후 청력이 회복된 것으로, grade IV를 회복이 없는 것으로 정의한 다음 그룹 $\mathrm{A}$, $\mathrm{B}, \mathrm{C}$ 에 대하여 각각 회복률을 조사한 결과 그룹 $\mathrm{A}$ 에서 $\mathrm{SGB}$ 그룹은 $100 \%$, non-SGB그룹은 $88.2 \%$, 그룹 B에서는 SGB $55.2 \%$, non-SGB 58.6\%, 그룹 C에서는 SGB 50.0\%, non$\mathrm{SGB} 58.3 \%$ 의 회복률을 보였다. 그룹 $\mathrm{A}, \mathrm{B}, \mathrm{C}$ 각 그룹 내에

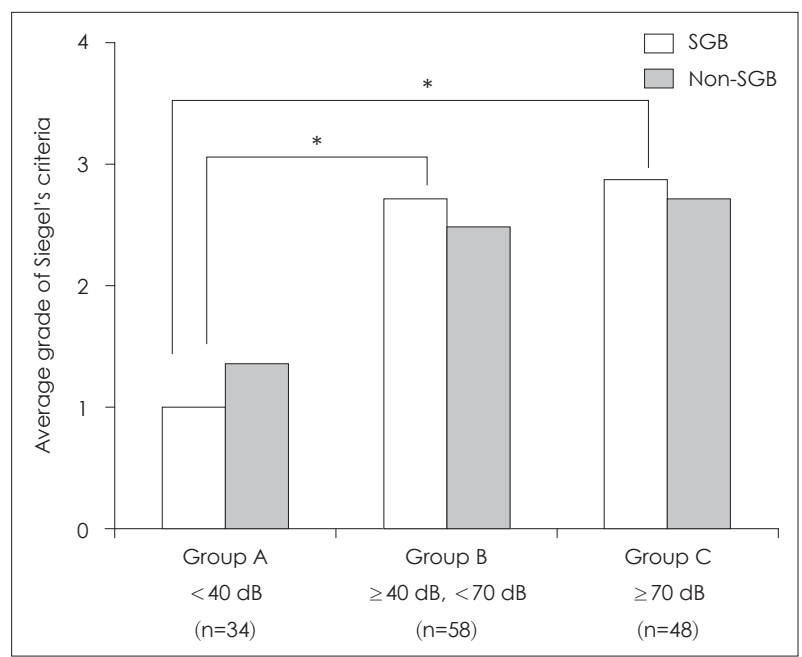

Fig. 4. Average grade of Siegel's criteria. Group B and C showed higher gradations than group $A(p<0.05$, Mann Whitney $U$ test), but no differences were seen between the SGB and non-SGB groups ( $p>0.05, \chi^{2}$ test). ${ }^{*} p<0.05$ by M-W test.

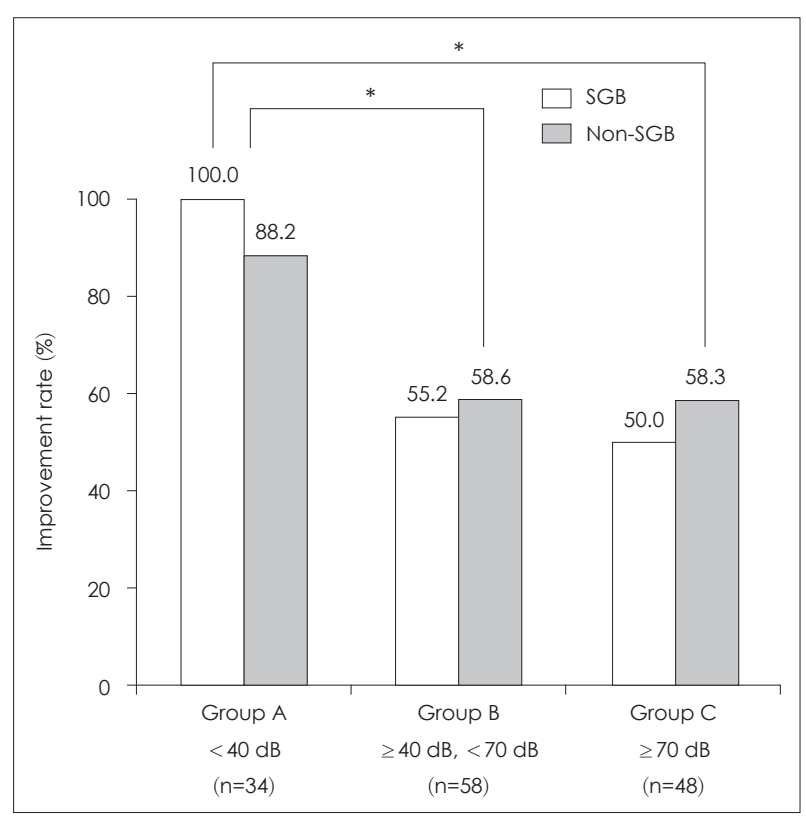

Fig. 5. There were no significant differences in improvement rate between SGB and non-SGB groups within groups A, B, and C $\left(p>0.05, \chi^{2}\right.$ test), but group B and C showed lower improvement rate than group $A(p<0.05$, Mann Whitney $U$ test) but group $B$ and C showed lower improvement rate than group A $(p<0.05$, Mann Whitney U test). 
서 SGB, non-SGB 그룹 간 유의미한 차이는 보이지 않았다 (Fig. 5).

청력역치에 따른 그룹별 Siegel's criteria의 grade 분포

그룹 $\mathrm{A}, \mathrm{B}, \mathrm{C}$ 에서 Siegel's criteria의 grade가 어떻게 분포 되었는지 알아보았으며, 그룹 A의 34명 중 grade I이 32명, grade 4가 2명이었고, 그룹 B 58명 중 grade I이 16명, grade II 16 명, grade III 1명, grade IV 25명이었으며, 그룹 C의 48명 중 grade I이 13명, grade II 6명, grade III 7명, grade IV 22명 이었다. 그룹 $\mathrm{A}$ 가 그룹 $\mathrm{B}, \mathrm{C}$ 에 비해 grade I로 완전 회복을 보이는 환자의 수가 많은 것을 알 수 있었다. 또한 그룹 $\mathrm{B}, \mathrm{C}$ 에서는 grade 4가 제일 많았다(Fig. 6). 따라서 그룹 B의 회 복률은 $56.90 \%$, 그룹 $\mathrm{C}$ 의 회복률은 $54.17 \%$ 로 그룹 $\mathrm{A}$ 의 회 복률 $94.12 \%$ 에 비해 유의하게 회복률이 떨어지는 것을 알

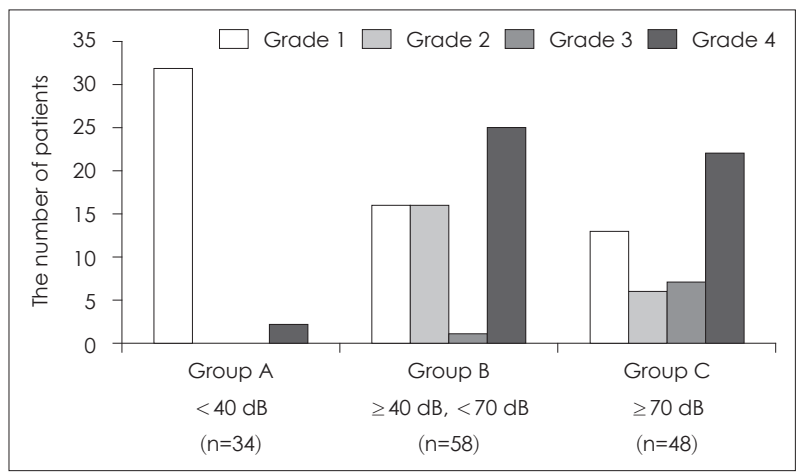

Fig. 6. Group A showed a large number of patients showing full recovery with grade 1 compared to groups $B$ and $C$. Also, grade 4 was the most common in groups $\mathrm{B}$ and $\mathrm{C}$.

Table 4. Improvement rates for groups A, B, and C

\begin{tabular}{lc}
\hline & Improvement rate (\%) \\
\hline Group A & 94.12 \\
Group B & 56.90 \\
Group C & 54.17 \\
\hline
\end{tabular}

Table 5. Prognostic factors using multiple regression analysis

\begin{tabular}{|c|c|c|}
\hline \multirow{2}{*}{ Variable } & \multicolumn{2}{|c|}{ Hearing recovery } \\
\hline & $\beta$ & $p$ value \\
\hline Age & 0.299 & $<0.001$ \\
\hline Onset & & NS \\
\hline Steroid (mg/kg) & & NS \\
\hline Number of ITDI & & NS \\
\hline Initial PTA at $500 \mathrm{~Hz}(\mathrm{~dB})$ & -0.270 & 0.028 \\
\hline Initial PTA at $1000 \mathrm{~Hz}(\mathrm{~dB})$ & & NS \\
\hline Initial PTA at $2000 \mathrm{~Hz}(\mathrm{~dB})$ & & NS \\
\hline Initial PTA at $4000 \mathrm{~Hz}(\mathrm{~dB})$ & 0.250 & 0.020 \\
\hline Initial average PTA (dB) & 0.428 & $<0.001$ \\
\hline
\end{tabular}

ITDI, intratympanic dexamethasone injection; NS, non specific; PTA, pure-tone audiometry threshold
수 있었다 $(p<0.05$, Wilcoxon's signed rank test) (Table 4).

\section{청력 회복과 연관성이 있는 인자들}

다중회귀분석을 이용하여 청력 회복과 연관성이 있는 인 자들을 살펴보았으며, 기존 연구로 알려진 나이, 초기 청력역 치 평균값 외에도 $500,4000 \mathrm{~Hz}$ 주파수의 초기 청력역치값 이 회복률과 연관성을 갖는 것으로 나타났다(Table 5).

\section{Profound hearing loss 환자들에 대한 연구}

추가로 SGB 그룹, non-SGB 그룹에서 $90 \mathrm{~dB}$ 이상의 profound hearing loss 환자들에 대해 연구를 하였는데, Siegel's criteria의 grade 평균값이 SGB 그룹(n=11)은 3.09, non-SGB 그룹(n=12)은 3.25 였으며, 치료 전후 청력역치 평균값의 차이 인 P average는 SGB 그룹 26.59, non-SGB 그룹 25.64로 두 그룹의 환자들 모두 치료 후에도 큰 호전을 보이지 않았다.

하지만 전신 스테로이드와 고실 내 스테로이드 주사에 초기 반응이 없던 환자들 중 3 명은 SGB 이후에 동 그룹의 평균 이 상으로 청력이 회복되는 것을 임상적으로 확인할 수 있었다.

환자 1 은 초기 청력역치 평균 $95 \mathrm{~dB}$ 에서 치료 시작 2 주 뒤 외래 $\mathrm{f} / \mathrm{u}$ 에서 시행한 순음청력검사상 청력역치 평균값이 32.5 $\mathrm{dB}, 3$ 주 뒤 $12.5 \mathrm{~dB}$ 로 회복이 되었고 환자 2 는 초기 청력역 치 평균 $91.67 \mathrm{~dB}$ 에서 치료 2주 뒤 $40.83 \mathrm{~dB}$ 로 회복이 되었 으며, 환자 3 은 초기 청력역치 평균 $96.67 \mathrm{~dB}$ 에서 치료 2 주 뒤 $53.33 \mathrm{~dB}$ 로 회복이 되었다(Fig. 7).

Non-SGB 그룹의 profound hearing loss 환자들 중에는 평균 이상으로 높은 청력 회복을 보이는 환자는 없었다.

\section{고 찰}

돌발성 난청은 특별한 원인 없이 감각신경성 난청이 갑자기 발생하는 것이 특징인 질환으로, 고실 내 스테로이드 주사와

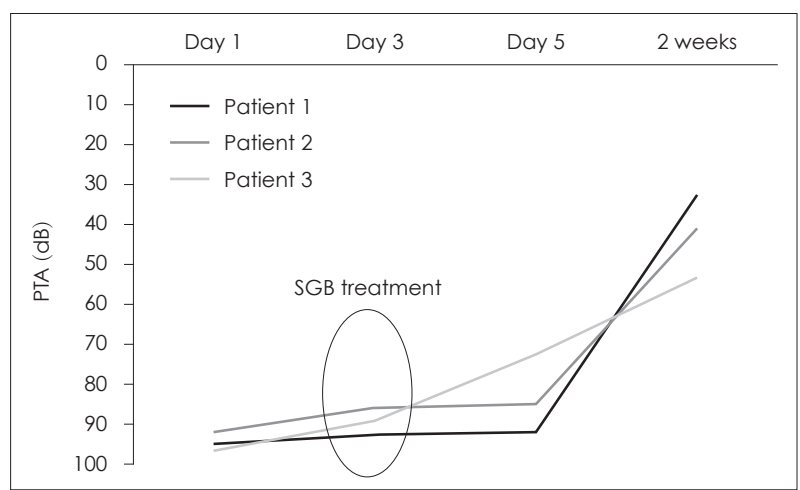

Fig. 7. 3 cases of recovery after SGB among patients with profound hearing loss. SGB, stellate ganglion block; PTA, pure-tone audiometry threshold. 
전신 스테로이드 요법 두 가지가 효과적인 치료법으로 알려져 있다. 이전부터 돌발성 난청의 원인 및 병태생리에 대한 가설 및 연구가 발표되고 있었으나 아직까지 확실한 병인은 밝혀 지지 않았으며, 내이의 혈류 장애가 허혈성 손상을 일으켜 돌 발성 난청을 유발한다는 이론에 근거하여 성상신경절차단술 을 돌발성 난청의 보조 요법으로 시행하고 있다.

성상신경절차단술(SGB)은 경추 교감신경총에 국소마취제 를 주사하여 교감신경절(sympathetic ganglia)과 신경절이전 섬유(preganglionic), 신경절이후섬유(postganglionic fiber) 의 신호를 차단함으로써 교감신경차단과 혈관확장을 통한 혈 류 증가를 일으키는 방법이다. 이로 인해 대상포진이나 작열 통으로 인해 발생하는 두경부, 상지의 통증을 조절하거나 상 부의 혈관연축, 허혈성 질환을 개선시킬 수 있으며, 또한 내이 혈류 장애도 개선시키는 것으로 알려져 있다. ${ }^{16)}$

$\mathrm{SGB}$ 를 시행 후 발생 가능한 합병증으로는 횡격신경 손상, 반회후두신경 손상, 부분적인 상박신경총차단이 발생할 수 있으며, 안면건조, 비충혈, 애성 등의 증상도 나타날 수 있다. 시술 중 발생 가능한 합병증으로는 기흥, 혈관천공, 척추강내 주사 등이 있으며 출혈에 의한 혈종 가능성도 있다. ${ }^{13)}$ 하지만 초음파를 이용하며 시행하게 된 뒤 합병증은 크게 감소하였 다고 알려졌으며 본원에서 $\mathrm{SGB}$ 를 시행한 뒤에도 합병증은 한 명도 발생하지 않았다.

이전에 난청 환자에서 $\mathrm{SGB}$ 의 효과에 대한 연구를 살펴보 면 Haug 등근 76 명의 돌발성 난청 환자에서 1일 2회, 3-5일 간 $\mathrm{SGB}$ 를 시행하여 $73 \%$ 에서 $10 \mathrm{~dB}$ 이상의 청력 호전이 있 었다고 보고했으며, Nam 등근 $\mathrm{SGB}$ 그룹 96 명에게 $1 \%$ mepivacaine $8 \mathrm{~mL}$ 를 10일간 사용하였으며 Siegel's criteria grade I-III을 회복이 되었다고 정의했을 때 회복률이 $61.5 \%$ 로 대조군 $42.9 \%$ 에 비해 SGB 그룹의 회복률이 유의하게 높 았다고 발표하였다. 그러나 Chung 등은 $\mathrm{SGB}$ 그룹에게 10일 간 하루에 1-2회 SGB를 시행했고, SGB 그룹과 대조군 사이 에 유의미한 회복률 차이가 없었다는 연구를 발표하였고, Lee 등 ${ }^{13}$ 은 1 일 1회, 10-15일간 SGB를 시행하였고, 발병 후 1 주에서 4주 사이에 치료를 시작한 군과 초기 청력소실 정도 가 고도난청 이하인 군에서만 회복률에 유의한 차이가 있었 다고 보고하였으며, Takinami ${ }^{16}$ 는 SGB 그룹 48 명에게 전신 스테로이드 요법과 병행하여 SGB를 1주에 1회 $1 \%$ lidocaine $7 \mathrm{~mL}$ 를 이용하여 총 20회 시행하였고, 전신스테로이드 단독 요법을 시행한 대조군과 비교하여 회복률에는 큰 차이가 없 었다고 보고하는 등, 연구마다 결과와 방법에 모두 차이를 보 였다.

이에 따라, 본 연구에서는 현재 돌발성 난청에 효과적이라 고 알려진 전신 스테로이드 요법과 고실 내 스테로이드 주사
를 모든 환자에 시행하며, 보조요법으로서의 $\mathrm{SGB}$ 의 효과에 대해 알아보고자 하였다. 또한 $\mathrm{SGB}$ 에 회복률이 높은 환자 그룹의 특징 및 청력 회복과 연관성이 있는 인자에 대해 같 이 연구를 시행하였다.

연구 결과, 연령, 고혈압, 당뇨, 고지혈증, 심혈관계 질환 등 을 매칭하여 교란변수에 의한 차이가 없게 한 뒤 SGB 그룹 과 non-SGB 그룹을 비교하였을 때 회복률에는 유의미한 차 이가 보이지 않았다. 또한 치료 전 초기 청력역치 평균에 대 해 $40 \mathrm{~dB}$ 미만, $40 \mathrm{~dB}$ 이상 $70 \mathrm{~dB}$ 미만, $70 \mathrm{~dB}$ 이상으로 각 그룹을 나누어서 회복률을 비교하였을 때도 차이는 보이지 않았다. 또한 초기 청력역치가 $40 \mathrm{~dB}$ 미만인 그룹은 $40 \mathrm{~dB}$ 이상인 그룹에 비해 회복률이 유의하게 높았다. 이는 돌발성 난청에서 초기청력이 나쁠수록 청력 회복의 예후가 좋지 않 았다는 이전 연구결과 ${ }^{19}$ 와 일치하는 것이다.

그러나 초기 청력역치평균이 $90 \mathrm{~dB}$ 이상으로 profound hearing loss를 보이는 환자들 중 일부는 $32.5,40.8,53.3 \mathrm{~dB}$ 로 같은 군의 청력 회복 정도에 비해 크게 회복된 것을 볼 수 있었다. 이는 SGB 치료가 돌발성 난청의 원인 중 하나인 내 이 혈류장애를 개선시켜 청력이 개선됐을 것으로 생각된다.

조사한 바에 따르면, 과거 연구들은 전신 스테로이드 요법 만 시행한 뒤 SGB의 회복률에 대해 연구를 시행했었다. SGB 의 청력 회복 효과에 대한 연구는 2012년 이후로 발표되지 않 았으며, ${ }^{12,16)}$ 또한 최근 돌발성 난청의 치료에 가장 많이 시행 되고 있는 전신 스테로이드 요법과 고실 내 스테로이드 주사 요법에 추가하여, $\mathrm{SGB}$ 를 보조요법으로 시행한 결과에 대한 연구는 이전에 발표된 적이 없다. 하지만 본 연구는 돌발성 난청 환자에 대해 전신 스테로이드 요법과 고실 내 스테로이드 주사를 시행하며 보조요법으로서의 $\mathrm{SGB}$ 의 효과에 대해 조 사한 첫 번째 연구이며, 또한 청력 회복에 영향을 미치는 인 자로 알려진 기저질환, 연령, 초기청력 등을 두 그룹 간 매칭 하여 교란변수에 의한 결과값 오류 가능성을 제거하였기 때 문에 실제 임상에서 $\mathrm{SGB}$ 의 효과에 대해 더 정확한 정보를 제공할 것으로 생각된다. 그리고 스테로이드 요법에 잘 반응 하지 않는 $90 \mathrm{~dB}$ 이상의 profound hearing loss 환자에서 $\mathrm{SGB}$ 시행한 후에 청력이 개선된 환자들을 관찰하였기에, 이 런 profound hearing loss 환자의 치료에 있어 $\mathrm{SGB}$ 의 가능 성을 확인한 의미가 있다.

본 연구의 한계점으로는 다음과 같다. 첫째, 돌발성 난청 환자에서 SGB 치료에 명확한 프로토콜이 정립되어 있지 않 아 다른 연구와 기준을 정확히 맞추지 못하였다. 본 연구에서 는 내원 3일 혹은 4일째부터 마취통증의학과 의뢰하에 SGB 를 시행하였다. 둘째, 대부분의 환자가 퇴원 후 3 주에서 한 달 까지 외래 추적 관찰이 가능했으나 그 이후의 청력 변화에 
대해서는 확인을 하지 못하였다. 셋째, 연구대상자가 총 318 명 에서 매칭 이후에는 각 그룹당 70 명씩, 총 140 명으로 많은 수 의 환자들이 연구에서 제외되었다. 즉, 연구대상을 선정하는 과정에서 특정대상이 선택적으로 뽑힘으로써 발생하는 $\mathrm{se}^{-}$ lection bias가 발생할 수 있다.

더 정확한 결과를 도출하기 위해 추후 지속적인 연구를 통해 청력저하와 내이 혈류장애와의 연관성에 대한 연구 및 $\mathrm{SGB}$ 치료의 명확한 프로토콜을 세워야 할 것이다. 또한 지 속적인 임상결과 분석 및 장기적인 $\mathrm{SGB}$ 효과에 대한 의무기 록 수집, 그에 따른 보조요법으로서의 $\mathrm{SGB}$ 치료의 효과에 대해서도 꾸준한 연구가 필요할 것으로 생각된다.

\section{Acknowledgments}

This study was supported by the National Research Foundation of Korea (NRF) grant funded by the Korea government (MSIT) (No. NRF-2020R1A2C2102660).

\section{Author Contribution}

Conceptualization: all authors. Data curation: Seung Yoon Han, Juyong Chung. Formal analysis: Seung Yoon Han, Juyong Chung. Funding acquisition: Juyong Chung. Investigation: Jin Lee, Hyungbon Koo. Methodology: Seung Yoon Han, Juyong Chung. Project administration: Juyong Chung. Resources: all authors. Software: Seung Yoon Han, Juyong Chung. Supervision: Juyong Chung. Validation: Juyong Chung. Visualization: Seung Yoon Han. Writingoriginal draft: Seung Yoon Han, Hyungbon Koo. Writing - review $\&$ editing: Seung Yoon Han, Juyong Chung, Jin Lee.

\section{ORCIDs}

Juyong Chung

https://orcid.org/0000-0001-5099-5243

Seung Yoon Han https://orcid.org/0000-0001-5507-3416

Jin Lee https://orcid.org/0000-0003-2264-8310

Hyungbon Koo

$$
\text { https://orcid.org/0000-0002-1342-9450 }
$$

\section{REFERENCES}

1) Wilson WR. Why treat sudden hearing loss. Am J Otol 1984;5(6): 481-3.

2) Moskowitz D, Lee KJ, Smith HW. Steroid use in idiopathic sudden sensorineural hearing loss. Laryngoscope 1984;94(5 Pt 1):664-6.

3) Schuknecht HF, Donovan ED. The pathology of idiopathic sudden sensorineural hearing loss. Arch Otorhinolaryngol 1986;243(1):115.
4) Shin SO. Clinical characteristics and management of sudden sensorineural hearing loss. Korean J Audiol 2011;15(1):1-7.

5) Wilson WR, Byl FM, Laird N. The efficacy of steroids in the treatment of idiopathic sudden hearing loss. A double-blind clinical study. Arch Otolaryngol 1980;106(12):772-6.

6) Tucci DL, Farmer JC Jr, Kitch RD, Witsell DL. Treatment of sudden sensorineural hearing loss with systemic steroids and valacyclovir. Otol Neurotol 2002;23(3):301-8.

7) Fisch U. Management of sudden deafness. Otolaryngol Head Neck Surg 1983;91(1):3-8.

8) Meyerhoff WL. "How I do it"--otology and neurology: A specific issue and its solution. The Management of Sudden Deafness. Laryngoscope 1979;89(2 Pt 1):1867-8.

9) Stachler RJ, Chandrasekhar SS, Archer SM, Rosenfeld RM, Schwartz SR, Barrs DM, et al. Clinical practice guideline: Sudden hearing loss. Otolaryngol Head Neck Surg 2012;146(3 Suppl):S1-35.

10) Cook TG, de Sanctis CA, Plaza JA, Sawyer DD. Stellate ganglion block for sudden profound hearing loss. Anesthesiology 1981;54(5): 421-3.

11) Haug O, Draper WL, Haug SA. Stellate ganglion blocks for idiopathic sensorineural hearing loss. Arch Otolaryngol 1976; 102(1):5-8.

12) Park KH, Lee CK, Lee JD, Park MK, Lee BD. Combination therapy with systemic steroids, an antiviral agent, anticoagulants, and stellate ganglion block for treatment of sudden sensorineural hearing loss. Korean J Audiol 2012;16(2):71-4.

13) Lee HK, Yang HD, Kim MS, Han JW, Chon KM, Kim HN. The efficacy of stellate ganglion block in the treatment of idiopathic sudden sensorineural hearing loss. Korean J OtorhinolaryngolHead Neck Surg 1999;42(3):311-6.

14) Aoki D, Takegoshi H, Kikuchi S. Evaluation of super-high-dose steroid therapy for sudden sensorineural hearing loss. Otolaryngol Head Neck Surg 2006;134(5):783-7.

15) Niedermeyer HP, Zahneisen G, Luppa P, Busch R, Arnold W. Cortisol levels in the human perilymph after intravenous administration of prednisolone. Audiol Neurootol 2003;8(6):31621.

16) Takinami Y. Evaluation of effectiveness of stellate ganglion block (SGB) treatment of sudden hearing loss. Acta Otolaryngol 2012; 132(1):33-8.

17) Nam SB, Yoon DM, Lee YW, Kim JS, Nam YT. The efficacy of stellate ganglion block in the treatment of idiopathic sudden sensorineural hearing loss. Korean J Pain 1998;11(1):30-5.

18) Chung SY, Yoon DM, Lee MH, Oh HK. The efficacy of stellate ganglion block in the treatment of idiopathic sudden sensorineural hearing loss. Korean J Pain 1995;8(1):65-73.

19) Kuhn M, Heman-Ackah SE, Shaikh JA, Roehm PC. Sudden sensorineural hearing loss: A review of diagnosis, treatment, and prognosis. Trends Amplif 2011;15(3):91-105. 